\title{
The Evaluation of Medical Inpatients Who Are Admitted on Long-Term Opioid Therapy for Chronic Pain
}

\author{
Hilary J. Mosher, MD,2, Shoshana J. Herzig, MD, MPH ${ }^{3,4}$, Itai Danovitch, MD, MBA ${ }^{5}$, Christina Boutsicaris, MD, \\ Sameer Hassamal, MD, Karl Wittnebel, MD, MPH${ }^{5}$, Azadeh Dashti, MD5, Teryl Nuckols, MD, MSHS 5,6*
}

\begin{abstract}
${ }^{1}$ Department of General Internal Medicine, University of lowa Carver College of Medicine, lowa City, lowa; ${ }^{2}$ lowa City VA Medical Center, lowa City, lowa; ${ }^{3}$ Beth Israel Deaconess Medical Center, Boston, Massachusetts; ${ }^{4}$ Harvard Medical School, Harvard University, Boston, Massachusetts; ${ }^{5}$ Division of General Internal Medicine, Cedars-Sinai Medical Center, Los Angeles, California; ${ }^{6}$ RAND Corporation, Santa Monica, California.
\end{abstract}

Individuals who are on long-term opioid therapy (LTOT) for chronic noncancer pain are frequently admitted to the hospital with acute pain, exacerbations of chronic pain, or comorbidities. Consequently, hospitalists find themselves faced with complex treatment decisions in the context of uncertainty about the effectiveness of LTOT as well as concerns about risks of overdose, opioid use disorders, and adverse events. Our multidisciplinary team sought to synthesize guideline recommendations and primary literature relevant to assessing medical inpatients on LTOT, with the objective of assisting practitioners in balancing effective pain treatment and opioid risk reduction. We identified no primary studies or guidelines specific to assessing medical inpatients on LTOT. Recommendations from outpatient guidelines on LTOT and guidelines on pain management in acute-care settings include the following: evaluate both pain and functional status, differentiate acute from chronic pain, investigate the preadmission course of opioid therapy, obtain a psychosocial history, screen for mental health conditions, screen for substance use disorders, check state prescription drug monitoring databases, order urine drug immunoassays, detect use of sedative-hypnotics, and identify medical conditions associated with increased risk of overdose and adverse events. Although approaches to assessing medical inpatients on LTOT can be extrapolated from related guidelines, observational studies, and small studies in surgical populations, more work is needed to address these critical topics for inpatients on LTOT. Journal of Hospital Medicine 2018;13:249-255. Published online first December 6, 2017. (C) 2018 Society of Hospital Medicine
H

ospitalists face complex questions about how to evaluate and treat the large number of individuals who are admitted on long-term opioid therapy (LTOT, defined as lasting 3 months or longer) for chronic noncancer pain. A recent study at one Veterans Affairs hospital, found $26 \%$ of medical inpatients were on LTOT. ${ }^{1}$ Over the last 2 decades, use of LTOT has risen substantially in the United States, including among middle-aged and older adults. ${ }^{2}$ Concurrently, inpatient hospitalizations related to the overuse of prescription opioids, including overdose, dependence, abuse, and adverse drug events, have increased by $153 \%{ }^{3}$ Individuals on LTOT can also be hospitalized for exacerbations of the opioid-treated chronic pain condition or unrelated conditions. In addition to affecting rates of hospitalization, use of LTOT is associated with higher rates of in-hospital adverse events, longer hospital stays, and higher readmission rates. ${ }^{1,4,5}$

Physicians find managing chronic pain to be stressful, are of-

*Address for correspondence: Teryl Nuckols, MD, MSHS, Cedars-Sinai Medical Center, 8700 Beverly Drive, Becker 113, Los Angeles, CA 90048; Telephone: 310-423-2760; Fax: 310-423-0436; E-mail: teryl.nuckols@cshs.org

Received: June 19, 2017; Revised: August 24, 2017;

Accepted: August 27, 2017

2018 Society of Hospital Medicine DOI 10.12788/jhm.2889 ten concerned about misuse and addiction, and believe their training in opioid prescribing is inadequate. ${ }^{6}$ Hospitalists report confidence in assessing and prescribing opioids for acute pain but limited success and satisfaction with treating exacerbations of chronic pain. ${ }^{7}$ Although half of all hospitalized patients receive opioids, ${ }^{5}$ little information is available to guide the care of hospitalized medical patients on LTOT for chronic noncancer pain. ${ }^{8,9}$

Our multispecialty team sought to synthesize guideline recommendations and primary literature relevant to the assessment of medical inpatients on LTOT to assist practitioners balance effective pain treatment and opioid risk reduction. This article addresses obtaining a comprehensive pain history, identifying misuse and opioid use disorders, assessing the risk of overdose and adverse drug events, gauging the risk of withdrawal, and based on such findings, appraise indications for opioid therapy. Other authors have recently published narrative reviews on the management of acute pain in hospitalized patients with opioid dependence and the inpatient management of opioid use disorder. ${ }^{10,11}$

\section{METHODS}

To identify primary literature, we searched PubMed, EMBASE, The Cochrane Central Register of Controlled Trials, Cochrane Database of Systematic Reviews, Database of Abstracts of Reviews of Effects, Health Economic Evaluations Database, key 
TABLE 1. List of Guidelines and Position Statements Potentially Applicable to Hospitalized Adults on Opioids for Chronic Pain

\begin{tabular}{|c|c|c|c|c|}
\hline Guideline & Development Body & Abbreviation & $\begin{array}{c}\text { Year of } \\
\text { Publication }\end{array}$ & Citation \\
\hline \multicolumn{5}{|l|}{ Hospital settings } \\
\hline Guidelines for Opioid Management within a Hospital Setting & $\begin{array}{l}\text { Massachusetts Health \& Hospital Association Substance Use } \\
\text { Disorder Prevention and Treatment Task Force }\end{array}$ & MHHA & 2016 & 11 \\
\hline Reducing Adverse Drug Events Related to Opioids Implementation Guide & $\begin{array}{l}\text { Society for Hospital Medicine's Center for Hospital Innovation \& } \\
\text { Improvement }\end{array}$ & SHM & 2015 & 12 \\
\hline $\begin{array}{l}\text { Clinical Policy: Critical Issues in the Prescribing of Opioids } \\
\text { for Adult Patients in the Emergency Department }\end{array}$ & $\begin{array}{l}\text { American College of Emergency Physicians Opioid Guideline } \\
\text { Writing Panel }\end{array}$ & ACEP2012 & 2012 & 13 \\
\hline \multicolumn{5}{|l|}{ Acute pain } \\
\hline Health Care Guide: Acute Pain Assessment and Opioid Prescribing Protocol & Institute for Clinical Systems Improvement & ICSI2014 & 2014 & 14 \\
\hline Optimizing the Treatment of Pain in Patients with Acute Presentations & $\begin{array}{l}\text { Joint Statement by the American College of Emergency Physicians, } \\
\text { American Pain Society, American Society for Pain Management } \\
\text { Nursing, and the Emergency Nurses Association }\end{array}$ & ACEP2010 & 2010 & 15 \\
\hline Acute Pain Management: Scientific Evidence, 3rd Edition & $\begin{array}{l}\text { Australian and New Zealand College of Anaesthetists and Faculty } \\
\text { of Pain Medicine }\end{array}$ & AUS/NZ & 2010 & 9 \\
\hline \multicolumn{5}{|l|}{ LTOT for chronic pain and published by a national body } \\
\hline VA/DoD Clinical Practice Guideline for Opioid Therapy for Chronic Pain & Department of Veterans Affairs and Department of Defense & VA & 2017 & 21 \\
\hline CDC Guideline for Prescribing Opioids for Chronic Pain & Centers for Disease Control and Prevention & CDC & 2016 & 20 \\
\hline Health Care Guide: Assessment and Management of Chronic Pain & Institute for Clinical Systems Improvement & ICSI2013 & 2013 & 22 \\
\hline Guidelines for Responsible Opioid Prescribing in Chronic Non-Cancer Pain & American Society of Interventional Pain Physicians & ASIPP & 2012 & 19 \\
\hline Practice Guidelines for Chronic Pain Management, An Updated Report & $\begin{array}{l}\text { American Society of Anesthesiologists Task Force on Chronic Pain } \\
\text { Management and the American Society of Regional Anesthesia } \\
\text { and Pain Medicine }\end{array}$ & ASA & 2010 & 23 \\
\hline $\begin{array}{l}\text { Canadian Guideline for Safe and Effective Use of Opioids } \\
\text { for Chronic Non-Cancer Pain }\end{array}$ & National Opioid Use Guideline Group, Canada & Canada & 2009 & 18 \\
\hline Pharmacological Management of Persistent Pain in Older Persons & $\begin{array}{l}\text { American Geriatrics Society Panel on the Pharmacological Manage- } \\
\text { ment of Persistent Pain in Older Persons }\end{array}$ & AGS & 2009 & 16 \\
\hline $\begin{array}{l}\text { Opioid Treatment Guidelines, Clinical Guidelines for the Use } \\
\text { of Chronic Opioid Therapy in Chronic Noncancer Pain }\end{array}$ & American Pain Society and the American Academy of Pain Medicine & APS-AAPM & 2009 & 17 \\
\hline
\end{tabular}

NOTE: Abbreviations: CDC, Centers for Disease Control and Prevention; DoD, Department of Defense; LTOT, long-term opioid therapy; VA, Veterans Affairs

meeting abstracts, and hand searches. To identify guidelines, we searched PubMed, National Guidelines Clearinghouse, specialty societies' websites, the Centers for Disease Control and Prevention (CDC), the United Kingdom National Institute for Health and Care Excellence, the Canadian Medical Association, and the Australian Government National Health and Medical Research Council. Search terms related to opioids and chronic pain, which was last updated in October $2016 .{ }^{12}$

We selected English-language documents on opioids and chronic pain among adults, excluding pain in the setting of procedures, labor and delivery, life-limiting illness, or specific conditions. For primary literature, we considered intervention studies of any design that addressed pain management among hospitalized medical patients. We included guidelines and specialty society position statements published after January 1,2009 , that addressed pain in the hospital setting, acute pain in any setting, or chronic pain in the outpatient setting if published by a national body. Due to the paucity of documents specific to inpatient care, we used a narrative review format to synthesize information. Dual reviewers extracted guideline recommendations potentially relevant to medical inpatients on LTOT. We also summarize relevant assessment instruments, emphasizing very brief screening instruments, which may be more likely to be used by busy hospitalists.

\section{RESULTS}

We did not find any primary literature specific to the assessment of pain among medical inpatients on LTOT. We identified 14 eligible guidelines and position statements (see Table 1). Three documents address pain in the hospital setting, including an "implementation guide" from the Society for Hospital Medicine. ${ }^{13-15}$ Three documents address acute pain, $, 16,17$ and 8 
TABLE 2. Guideline and Position Statement Recommendations Relevant to Prescribing Opioids for Hospitalized Adults with Chronic or Recurring Pain

Statement

Guidelines Making Similar Recommendations

Obtaining a comprehensive pain history

Determine whether the clinical situation warrants emergent or urgent treatment with opioids without comprehensive assessment, such as if pain prevents the patient from providing a detailed history

ICSI2014, ACEP2010

Assess pain and functional status

MHHA, ICSI2014, AUS/NZ,

CDC, ASIPP, Canadian, AGS

Assess whether pain is worse than baseline, whether pain represents an exacerbation of chronic pain or new acute pain, and whether pain exacerbation may be a manifestation of withdrawal

ICSI2014, AUS/NZ, ASIPP

Obtain a detailed pain history including onset, pattern, intensity, location, quality, exacerbating and alleviating factors, prior treatments,

effects

Obtain a medical history from both the patient and caregivers

VA, CDC, Canadian

SHM, ICSI2014

Review the medical record and contact the primary outpatient prescriber to ascertain history of pain and treatment,

including opioids medications prescribed, doses, and frequencies

MHHA, SHM, ICSI2014, AUS/NZ, CDC, Canadian

Obtain detailed psychosocial history to identify additional stressors or pain contributors, and gain insight into pain coping skills

SHM, ICSI2014, CDC, Canadian, APS-AAPM

Screen for depression, suicidality, anxiety, and other mental health conditions

MHHA, SHM, ICSI2014

VA, CDC, Canadian

Identifying misuse and opioid use disorders

Screen for current and prior misuse of opioids, alcohol, and other controlled substances

MHHA, SHM, ICSI2014

VA, APS-AAPM

Check state PDMP databases

MHHA, SHM, ACEP2012,

ICSI2014, VA, CDC, ASIPP, APS-AAPM

Order urine drug immunoassay screening test for opioids and drugs of abuse

MHHA, ICSI2014

VA, CDC, ASIPP, Canadian, APS-AAPM

If there is evidence of misuse of opioids or other substances, share concerns with patient, assess whether patient meets criteria for opioid or other substance use disorder, and consider referral to a specialist

MHHA, ICSI2014, AUS/NZ

VA, CDC

\section{Assessing the risk of overdose and adverse events}

Carefully assess risks and benefits when opioid doses exceed $50 \mathrm{mg}$ of morphine equivalents per day

CDC

Inquire about use of sedative-hypnotics, including benzodiazepines, and alcohol

MHHA, ICSI2014,

VA, CDC, Canadian, AGS,

APS-AAPM

Check skin for fentanyl patches

SHM

Identify comorbidities that increase risk of overdose, including sleep disordered breathing and kidney, liver, and obstructive lung disease

Identify risk factors for other adverse events, such as advanced age, cognitive impairment, fall risk

MHHA, SHM, ICSI2014, AUS/NZ, Canadian

SHM, ICSI2014,

Canadian

NOTE: Abbreviations: ACEP2010, Joint Statement by the American College of Emergency Physicians, American Pain Society, American Society for Pain Management Nursing, and the Emergency Nurses Association; ACEP2012, American College of Emergency Physicians Opioid Guideline Writing Panel; AGS, American Geriatrics Society Panel on the Pharmacological Management of Persistent Pain in Older Persons; APS-AAPM, American Pain Society and the American Academy of Pain Medicine; ASIPP, American Society of Interventional Pain Physicians; AUS/NZ, Australian and New Zealand College of Anaesthetists and Faculty of Pain Medicine; Canada, National Opioid Use Guideline Group, Canada; CDC, Centers for Disease Control and Prevention; ICSI, Institute for Clinical Systems Improvement; MHHA, Massachusetts Health \& Hospital Association Substance Use Disorder Prevention and Treatment Task Force; PDMP, prescription drug monitoring program; SHM, Society for Hospital Medicine's Center for Hospital Innovation \& Improvement; VA, Department of Veterans Affairs and Department of Defense.

documents address LTOT for chronic noncancer pain. ${ }^{18-25}$ Table 2 lists guideline recommendations potentially relevant to inpatients on LTOT.

\section{DISCUSSION}

We grouped guideline recommendations into the following 3 categories applicable to inpatient assessment of patients on LTOT: obtaining a comprehensive pain history, identifying misuse and opioid use disorders, and assessing the risk of overdose and adverse drug events. Although we did not find recommendations that specifically spoke to assessment for opioid withdrawal and appraising indications for opioid therapy, we briefly discuss these areas as highly relevant to inpatient practice. 
TABLE 3. Instruments for Assessing Pain, Function, Psychological Health, Opioid Use Disorders, and Withdrawal

\begin{tabular}{llll}
\hline Instruments & Items & Scale & Positive Score \\
\hline Assessing pain intensity: Numerical rating scale & $\begin{array}{l}\text { Patient selects a whole number that best reflects the intensity } \\
\text { of the pain. }\end{array}$ & $\begin{array}{l}\text { ordinal by integer } \\
0=\text { no pain } \\
10=\text { worst pain imaginable }\end{array}$ & Variable \\
& & 25,26 \\
\hline
\end{tabular}

Assessing pain intensity and function: Pain average interference with enjoyment of life, and interference with general activity assessment scale ${ }^{a}$

\begin{tabular}{|c|c|c|c|c|}
\hline \multirow{5}{*}{$\begin{array}{l}\text { Assessing pain intensity and function: Pain average, } \\
\text { interference with enjoyment of life, and interference } \\
\text { with general activity assessment scale } e^{\text {a }}\end{array}$} & & Average of 3 items & Not reported & 28 \\
\hline & What number best describes your pain on average in the last week? & $0=$ no pain & & \\
\hline & & $10=$ pain as bad as you can imagine & & \\
\hline & $\begin{array}{l}\text { What number best describes how, during the past week, pain has } \\
\text { interfered with your enjoyment of life? }\end{array}$ & $\begin{array}{l}0=\text { does not interfere } \\
10=\text { completely interferes }\end{array}$ & & \\
\hline & $\begin{array}{l}\text { What number best describes how, during the past week, pain has } \\
\text { interfered with your general activity? }\end{array}$ & $\begin{array}{l}0=\text { does not interfere, } \\
10=\text { completely interferes }\end{array}$ & & \\
\hline $\begin{array}{l}\text { Screening for depression: Single item from screening } \\
\text { tool for psychological distress }\end{array}$ & $\begin{array}{l}\text { Over the past week, how much have you been bothered by feeling } \\
\text { sad, down, or uninterested in life? }\end{array}$ & $\begin{array}{l}0=\text { not at all } \\
9=\text { severely }\end{array}$ & $\geq 4$ & 30,31 \\
\hline $\begin{array}{l}\text { Screening for anxiety: Single item from screening tool } \\
\text { for psychological distress }\end{array}$ & $\begin{array}{l}\text { Over the past week, how much have you been bothered by feeling } \\
\text { anxious or nervous? }\end{array}$ & $\begin{array}{l}0=\text { not at all } \\
9=\text { severely }\end{array}$ & $\geq 5$ & 31 \\
\hline $\begin{array}{l}\text { Screening for misuse and opioid use disorders: } \\
\text { Single-item screening question for unhealthy drug use } \\
\text { in primary care patients } \mathrm{s}^{\mathrm{a}}\end{array}$ & $\begin{array}{l}\text { How many times in the past year have you used an illegal drug or } \\
\text { used a prescription medication for nonmedical reasons (eg, because } \\
\text { of the experience or feeling it caused)? }\end{array}$ & 0 to any number of times & $\geq 1$ & 39 \\
\hline
\end{tabular}

${ }^{a}$ Not yet tested among inpatients.

\section{Obtaining a Comprehensive Pain History}

Hospitalists newly evaluating patients on LTOT often face a dual challenge: deciding if the patient has an immediate indication for additional opioids and if the current long-term opioid regimen should be altered or discontinued. In general, opioids are an accepted short-term treatment for moderate to severe acute pain but their role in chronic noncancer pain is controversial. Newly released guidelines by the CDC recommend initiating LTOT as a last resort, and the Departments of Veterans Affairs and Defense guidelines recommend against initiation of LTOT.22,23

A key first step, therefore, is distinguishing between acute and chronic pain. Among patients on LTOT, pain can represent a new acute pain condition, an exacerbation of chronic pain, opioid-induced hyperalgesia, or opioid withdrawal. Acute pain is defined as an unpleasant sensory and emotional experience associated with actual or potential tissue damage or described in relation to such damage. ${ }^{26}$ In contrast, chronic pain is a complex response that may not be related to actual or ongoing tissue damage, and is influenced by physiological, contextual, and psychological factors. Two acute pain guidelines and 1 chronic pain guideline recommend distinguishing acute and chronic pain, 9,16,21 3 chronic pain guidelines reinforce the importance of obtaining a pain history (including timing, intensity, frequency, onset, etc), ${ }^{20,22,23}$ and 6 guidelines recommend ascertaining a history of prior pain-related treatments. 9,13,14,16,20,22 Inquiring how the current pain compares with symptoms "on a good day," what activities the patient can usually perform, and what the patient does outside the hospital to cope with pain can serve as entry into this conversation.
The standard for assessing pain intensity remains patient self-report using a validated instrument, such as the Numerical Rating Scale (Table 3). ${ }^{23,24,27}$ Among patients with chronic pain, clinically meaningful differences in pain intensity correspond to 1 - to 2-point changes on these scales. ${ }^{27,28}$ Pain scores should not be the only factor used to determine when opioids are indicated because other factors are relevant and scores may not correlate with patients' preference to receive opioid therapy. ${ }^{29}$ Along with pain intensity, 3 guidelines for hospital settings/ acute pain and 4 chronic pain guidelines recommend assessing functional status. 9,13,16,18,20-22 The CDC guideline endorses 3-item the "Pain average, interference with Enjoyment of life, and interference with General activity" (PEG) assessment scale 22,30 (Table 3). The instrument would need to be adapted for the hospital setting, but improvement in function, such as mobility, is a good indicator of clinical improvement among inpatients as well.

In addition to function, 5 guidelines, including 2 specific guidelines for acute pain or the hospital setting, recommend obtaining a detailed psychosocial history to identify life stressors and gain insight into the patient's coping skills. ${ }^{14,16,19,20,22}$ Psychiatric symptoms can intensify the experience of pain or hamper coping ability. Anxiety, depression, and insomnia frequently coexist in patients with chronic pain. ${ }^{31}$ As such, 3 hospital setting/acute pain guidelines and 3 chronic pain guidelines recommend screening for mental health issues including anxiety and depression. ${ }^{13,14,16,20,22,23}$ Several depression screening instruments have been validated among inpatients, ${ }^{32}$ and there are validated single-item, self-administered instruments for both depression and anxiety (Table 3).32,33 
Although obtaining a comprehensive history before making treatment decisions is ideal, some patients present in extremis. In emergency departments, some guidelines endorse prompt administration of analgesics based on patient self-report, prior to establishing a diagnosis. ${ }^{17}$ Given concerns about the growing prevalence of opioid use disorders, several states now recommend emergency medicine prescribers screen for misuse before giving opioids and avoid parenteral opioids for acute exacerbations of chronic pain. ${ }^{34}$ Treatments received in emergency departments set patients' expectations for the care they receive during hospitalization, and hospitalists may find it necessary to explain therapies appropriate for urgent management are not intended to be sustained.

\section{Identifying Misuse and Opioid Use Disorders}

Nonmedical use of prescription opioids and opioid use disorders have more than doubled over the last decade. ${ }^{35}$ Five guidelines, including 3 specific guidelines for acute pain or the hospital setting, recommend screening for opioid misuse. ${ }^{13,14,16,19,23}$ Many states mandate practitioners assess patients for substance use disorders before prescribing controlled substances. ${ }^{36}$ Instruments to identify aberrant and risky use include the Current Opioid Misuse Measure, ${ }^{37}$ Prescription Drug Use Questionnaire, ${ }^{38}$ Addiction Behaviors Checklist, ${ }^{39}$ Screening Tool for Abuse, ${ }^{40}$ and the Self-Administered Single-Item Screening Question (Table 3). ${ }^{41}$ However, the evidence for these and other tools is limited and absent for the inpatient setting. ${ }^{21,42}$

In addition to obtaining a history from the patient, 4 guidelines specific to hospital settings/acute pain and 4 chronic pain guidelines recommend practitioners access prescription drug monitoring programs (PDMPs). ${ }^{13-16,19,21-24}$ PDMPs exist in all states except Missouri, and about half of states mandate practitioners check the PDMP database in certain circumstances. ${ }^{36}$ Studies examining the effects of PDMPs on prescribing are limited, but checking these databases can uncover concerning patterns including overlapping prescriptions or multiple prescribers. ${ }^{43}$ PDMPs can also confirm reported medication doses, for which patient report may be less reliable.

Two hospital/acute pain guidelines and 5 chronic pain guidelines also recommend urine drug testing, although differing on when and whom to test, with some favoring universal screening. 11,20,23 Screening hospitalized patients may reveal substances not reported by patients, but medications administered in emergency departments can confound results. Furthermore, the commonly used immunoassay does not distinguish heroin from prescription opioids, nor detect hydrocodone, oxycodone, methadone, buprenorphine, or certain benzodiazepines. Chromatography/mass spectrometry assays can but are often not available from hospital laboratories. The differential for unexpected results includes substance use, self treatment of uncontrolled pain, diversion, or laboratory error. ${ }^{20}$

If concerning opioid use is identified, 3 hospital setting/ acute pain specific guidelines and the CDC guideline recommend sharing concerns with patients and assessing for a substance use disorder. $9,13,16,22$ Determining whether patients have an opioid use disorder that meets the criteria in the Diagnostic and Statistical Manual, 5th Edition ${ }^{44}$ can be challenging. $\mathrm{Pa}$ tients may minimize or deny symptoms or fear that the stigma of an opioid use disorder will lead to dismissive or subpar care. Additionally, substance use disorders are subject to federal confidentiality regulations, which can hamper acquisition of information from providers. ${ }^{45}$ Thus, hospitalists may find specialty consultation helpful to confirm the diagnosis.

\section{Assessing the Risk of Overdose and Adverse Drug Events}

Oversedation, respiratory depression, and death can result from iatrogenic or self-administered opioid overdose in the hospital.5 Patient factors that increase this risk among outpatients include a prior history of overdose, preexisting substance use disorders, cognitive impairment, mood and personality disorders, chronic kidney disease, sleep apnea, obstructive lung disease, and recent abstinence from opioids.12 Medication factors include concomitant use of benzodiazepines and other central nervous system depressants, including alcohol; recent initiation of long-acting opioids; use of fentanyl patches, immediate-release fentanyl, or methadone; rapid titration; switching opioids without adequate dose reduction; pharmacokinetic drug-drug interactions; and, importantly, higher doses.12,22 Two guidelines specific to acute pain and hospital settings and 5 chronic pain guidelines recommend screening for use of benzodiazepines among patients on LTOT.13,14,16,18-20,22,21 The CDC guideline recommends careful assessment when doses exceed $50 \mathrm{mg}$ of morphine equivalents per day and avoiding doses above $90 \mathrm{mg}$ per day due to the heightened risk of overdose. ${ }^{22}$ In the hospital, $23 \%$ of patients receive doses at or above $100 \mathrm{mg}$ of morphine equivalents per day, and concurrent use of central nervous system depressants is common. Changes in kidney and liver function during acute illness may impact opioid metabolism and contribute to overdose.

In addition to overdose, opioids are leading causes of adverse drug events during hospitalization. ${ }^{46}$ Most studies have focused on surgical patients reporting common opioid-related events as nausea/vomiting, pruritus, rash, mental status changes, respiratory depression, ileus, and urinary retention. ${ }^{47}$ Hospitalized patients may also exhibit chronic adverse effects due to LTOT. At least one-third of patients on LTOT eventually stop because of adverse effects, such as endocrinopathies, sleep disordered breathing, constipation, fractures, falls, and mental status changes. ${ }^{48}$ Patients may lack awareness that their symptoms are attributable to opioids and are willing to reduce their opioid use once informed, especially when alternatives are offered to alleviate pain.

\section{Gauging the Risk of Withdrawal}

Sudden discontinuation of LTOT by patients, practitioners, or intercurrent events can have unanticipated and undesirable consequences. Withdrawal is not only distressing for patients; it can be dangerous because patients may resort to illicit use, 
diversion of opioids, or masking opioid withdrawal with other substances such as alcohol. The anxiety and distress associated with withdrawal, or anticipatory fear about withdrawal, can undermine therapeutic alliance and interfere with processes of care. Reviewed guidelines did not offer recommendations regarding withdrawal risk or specific strategies for avoidance. There is no specific prior dose threshold or degree of reduction in opioids that puts patients at risk for withdrawal, in part due to patients' beliefs, expectations, and differences in response to opioid formulations. Symptoms of opioid withdrawal have been compared to a severe case of influenza, including stomach cramps, nausea and vomiting, diarrhea, tremor and muscle twitching, sweating, restlessness, yawning, tachycardia, anxiety and irritability, bone and joint aches, runny nose, tearing, and piloerection. ${ }^{49}$ The Clinical Opiate Withdrawal Scale (COWS) ${ }^{49}$ and the Clinical Institute Narcotic Assessment ${ }^{51}$ are clinician-administered tools to assess opioid withdrawal similar to the Clinical Institute Withdrawal Assessment of Alcohol Scale, Revised, ${ }^{52}$ to monitor for withdrawal in the inpatient setting.

\section{Synthesizing and Appraising the Indications for Opioid Therapy}

For medical inpatients who report adequate pain control and functional outcomes on current doses of LTOT, without evidence of misuse, the pragmatic approach is to continue the treatment plan established by the outpatient clinician rather than escalating or tapering the dose. If opioids are prescribed at discharge, 3 hospital setting/acute pain guidelines and the CDC guideline recommend prescribing the lowest effective dose of immediate release opioids for 3 to 7 days. ${ }^{13,15,16,22}$

When patients exhibit evidence of an opioid use disorder, have a history of serious overdose, or are experiencing intolerable opioid-related adverse events, the hospitalist may conclude the harms of LTOT outweigh the benefits. For these patients, opioid treatment in the hospital can be aimed at preventing withdrawal, avoiding the perpetuation of inappropriate opioid use, managing other acute medical conditions, and communicating with outpatient prescribers. For patients with misuse, discontinuing opioids is potentially harmful and may be perceived as punitive. Hospitalists should consider consulting addiction or mental health specialists to assist with formulating a plan of care. However, such specialists may not be available in smaller or rural hospitals and referral at discharge can be challenging. ${ }^{53}$

Beginning to taper opioids during the hospitalization can be appropriate when patients are motivated and can transition to an outpatient provider who will supervise the taper. In ambulatory settings, tapers of $10 \%$ to $30 \%$ every 2 to 5 days are generally well tolerated. ${ }^{54}$ If patients started tapering opioids under supervision of an outpatient provider prior to hospitalization; ideally, the taper can be continued during hospitalization with close coordination with the outpatient clinician.

Unfortunately, many patients on LTOT are admitted with new sources of acute pain and or exacerbations of chronic pain, and some have concomitant substance use disorders; we plan to address the management of these complex situations in future work.
Despite the frequency with which patients on LTOT are hospitalized for nonsurgical stays and the challenges inherent in evaluating pain and assessing the possibility of substance use disorders, no formal guidelines or empirical research studies pertain to this population. Guidelines in this review were developed for hospital settings and acute pain in the absence of LTOT, and for outpatient care of patients on LTOT. We also included a nonsystematic synthesis of literature that varied in relevance to medical inpatients on LTOT.

\section{CONCLUSIONS}

Although inpatient assessment and treatment of patients with LTOT remains an underresearched area, we were able to extract and synthesize recommendations from 14 guideline statements and apply these to the assessment of patients with LTOT in the inpatient setting. Hospitalists frequently encounter patients on LTOT for chronic nonmalignant pain and are faced with complex decisions about the effectiveness and safety of LTOT; appropriate patient assessment is fundamental to making these decisions. Key guideline recommendations relevant to inpatient assessment include assessing both pain and functional status, differentiating acute from chronic pain, ascertaining preadmission pain treatment history, obtaining a psychosocial history, screening for mental health issues such as depression and anxiety, screening for substance use disorders, checking state prescription drug monitoring databases, ordering urine drug immunoassays, detecting use of sedative-hypnotics, identifying medical conditions associated with increased risk of overdose and adverse events, and appraising the potential benefits and harms of opioid therapy. Although approaches to assessing medical inpatients on LTOT can be extrapolated from outpatient guidelines, observational studies, and small studies in surgical populations, more work is needed to address these critical topics for inpatients on LTOT.

Disclosure: Dr. Herzig was funded by grant number K23AG042459 from the National Institute on Aging. The funding organization had no involvement in any aspect of the study, including design and conduct of the study; collection, management, analysis, and interpretation of the data; and preparation, review, or approval of the manuscript. All other authors have no relevant conflicts of interest with the work.

\section{References}

1. Mosher HJ, Jiang L, Sarrazin MSV, Cram P, Kaboli PJ, Vander Weg MW. Prevalence and Characteristics of Hospitalized Adults on Chronic Opioid Therapy. J Hosp Med. 2014;9(2):82-87.

2. Campbell $\mathrm{Cl}$, Weisner $\mathrm{C}$, Leresche $\mathrm{L}$, et al. Age and Gender Trends in Long-Term Opioid Analgesic Use for Noncancer Pain. Am J Public Health. 2010;100(12):2541-2547.

3. Owens PL, Barrett ML, Weiss AJ, Washington RE, Kronick R. Hospital Inpatient Utilization Related to Opioid Overuse among Adults, 1993-2012. Rockville, MD: Agency for Healthcare Research and Quality; 2014

4. Gulur P, Williams L, Chaudhary S, Koury K, Jaff M. Opioid Tolerance--a Predictor of Increased Length of Stay and Higher Readmission Rates. Pain Physician. 2014;17(4):E503-507.

5. Herzig SJ, Rothberg MB, Cheung M, Ngo LH, Marcantonio ER. Opioid Utilization and Opioid-Related Adverse Events in Nonsurgical Patients in US Hospitals. J Hosp Med. 2014;9(2):73-81.

6. Jamison RN, Sheehan KA, Scanlan E, Matthews M, Ross EL. Beliefs and At- 
titudes About Opioid Prescribing and Chronic Pain Management: Survey of Primary Care Providers. J Opioid Manag. 2014;10(6):375-382.

7. Calcaterra SL, Drabkin AD, Leslie SE, et al. The Hospitalist Perspective on Opioid Prescribing: A Qualitative Analysis. J Hosp Med. 2016;11(8):536-542.

8. Helfand M, Freeman M. Assessment and Management of Acute Pain in Adult Medical Inpatients: A Systematic Review. Pain Med. 2009;10(7):1183-1199.

9. Macintyre P, Schug S, Scott D, Visser E, Walker S. Acute Pain Management: Scientific Evidence. Melbourne, Australia: Australian and New Zealand College of Anesthetists and Faculty of Pain Medicine; 2010.

10. Raub JN, Vettese TE. Acute Pain Management in Hospitalized Adult Patients with Opioid Dependence: A Narrative Review and Guide for Clinicians. $J$ Hosp Med. 2017;12(5):375-379.

11. Theisen-Toupal J, Ronan MV, Moore A, Rosenthal ES. Inpatient Management of Opioid Use Disorder: A Review for Hospitalists. J Hosp Med. 2017;12(5):369-374

12. Nuckols TK, Anderson L, Popescu I, et al. Opioid Prescribing: A Systematic Review and Critical Appraisal of Guidelines for Chronic Pain. Ann Intern Med. 2014;160(1):38-47.

13. Massachusetts Health \& Hospital Association Substance Use Disorder Prevention and Treatment Task Force. Guidelines for Opioid Management with in a Hospital Setting. Boston, MA: Massachusetts Health \& Hospital Association; 2009.

14. Society for Hospital Medicine's Center for Hospital Innovation \& Improvement. Reducing Adverse Drug Events Related to Opioids Implementation Guide. Philadelphia, PA; 2015.

15. Cantrill S, Brown M, Carlisle RJ, et al. Clinical Policy Critical Issues in the Prescribing of Opioids for Adult Patients in the Emergency Department. Ann Emerg Med. 2012;60(4):499-525.

16. Thorson D, Biewen P, Bonte B, et al. Acute Pain Assessment and Opioid Prescribing Protocol. Bloomington, MN: Institute for Clinical Systems Improvement; 2014.

17. American Society for Pain Management N, Emergency Nurses A, American College of Emergency P, American Pain S. Optimizing the Treatment of Pain in Patients with Acute Presentations. Policy Statement. Ann Emerg Med. Jul 2010;56(1):77-79.

18. American Geriatrics Society Panel on the Pharmacological Management of Persistent Pain in Older Persons. Pharmacological Management of Persistent Pain in Older Persons. J Am Geriatr Soc. 2009;57(8):1331-1346.

19. Chou R, Fanciullo GJ, Fine PG, et al. Clinical Guidelines for the Use of Chronic Opioid Therapy in Chronic Noncancer Pain. J Pain. 2009;10(2):113-130.

20. Furlan AD, Reardon R, Weppler C. Opioids for Chronic Noncancer Pain: A New Canadian Practice Guideline. CMAJ. 2010;182(9):923-930.

21. Manchikanti L, Abdi S, Atluri S, et al. American Society of Interventional Pain Physicians (ASIPP) Guidelines for Responsible Opioid Prescribing in Chronic Non-Cancer Pain: Part 2--Guidance. Pain Physician. 2012;15(3 Suppl):S67-116.

22. Dowell D, Haegerich TM, Chou R. CDC Guideline for Prescribing Opioids for Chronic Pain--United States, 2016. JAMA. 2016:315(15):1624-1645.

23. The Opiod Therap for Chronic Pain Work Group. VA/DoD Clinical Practice Guideline for Opioid Therapy for Chronic Pain. Version 3.0. https://www. healthquality.va.gov/guidelines/Pain/cot/NADoDOTCPG022717.pdf. AccessedAugust 3, 2016.

24. Hooten W, Timming R, Belgrade M, et al. Assessment and Managemeent of Chronic Pain. Bloomington, MN: Institute for Clinical Systems Improvement; 2013.

25. American Society of Anesthesiologists Task Force. Practice Guidelines for Chronic Pain Management: An Updated Report by the American Society of Anesthesiologists Task Force on Chronic Pain Management and the American Society of Regional Anesthesia and Pain Medicine. Anesthesiology. 2010;112(4):810-833.

26. International Association for the Study of Pain. IASP Taxonomy. https://www. iasp-pain.org/Taxonomy. Accessed August 3, 2016

27. Hawker GA, Mian S, Kendzerska T, French M. Measures of Adult Pain: Visual Analog Scale for Pain (VAS Pain), Numeric Rating Scale for Pain (NRS Pain), Mcgill Pain Questionnaire (MPQ), Short-Form Mcgill Pain Questionnaire (SFMPQ), Chronic Pain Grade Scale (CPGS), Short Form-36 Bodily Pain Scale (SF36 BPS), and Measure of Intermittent and Constant Osteoarthritis Pain (ICOAP). Arthritis Care Res (Hoboken). 2011;63 Suppl 11:S240-252.

28. Farrar JT, Young JP, LaMoreaux L, Werth JL, Poole RM. Clinical Importance of Changes in Chronic Pain Intensity Measured on an 11-Point Numerical Pain Rating Scale. Pain. 2001:94(2):149-158.

29. van Dijk JF, Kappen TH, Schuurmans MJ, van Wijck AJ. The Relation between Patients' NRS Pain Scores and Their Desire for Additional Opioids after Surgery. Pain Pract. 2015;15(7):604-609.
30. Krebs EE, Lorenz KA, Bair MJ, et al. Development and Initial Validation of the PEG, a Three-Item Scale Assessing Pain Intensity and Interference. J Gen Intern Med. 2009:24(6):733-738.

31. Finan PH, Smith MT. The Comorbidity of Insomnia, Chronic Pain, and Depression: Dopamine as a Putative Mechanism. Sleep Med Rev. 2013;17(3): 173-183.

32. IsHak WW, Collison K, Danovitch I, et al. Screening for Depression in Hospitalized Medical Patients. J Hosp Med. 2017;12(2):118-125.

33. Young QR, Nguyen M, Roth S, Broadberry A, Mackay MH. Single-Item Measures for Depression and Anxiety: Validation of the Screening Tool for Psychological Distress in an Inpatient Cardiology Setting. Eur J Cardiovasc Nurs. 2015;14(6):544-551.

34. Poon SJ, Greenwood-Ericksen MB. The Opioid Prescription Epidemic and the Role of Emergency Medicine. Ann Emerg Med. 2014;64(5):490-495.

35. National Institute on Alcohol Abuse and Alcoholism (NIAAA). Rates of Nonmedical Prescription Opioid Use and Opioid Use Disorder Double in 10 Years. https://www.nih.gov/news-events/rates-nonmedical-prescription-opioid-use-opioid-use-disorder-double-10-years. Accessed on August 3, 2016.

36. National Alliance for Model State Drug Laws. Status of Prescription Drug Monitoring Programs (PDMPs). http://www.pdmpassist.org/pdf/PDMPProgramStatus.pdf. Accessed August 3, 2016.

37. Butler SF, Budman SH, Fernandez KC, et al. Development and Validation of the Current Opioid Misuse Measure. Pain. 2007;130(1-2):144-156.

38. Compton PA, Wu SM, Schieffer B, Pham $Q$, Naliboff BD. Introduction of a Self-Report Version of the Prescription Drug Use Questionnaire and Relationship to Medication Agreement Noncompliance. J Pain Symptom Manage. 2008;36(4):383-395.

39. Wu SM, Compton P, Bolus R, et al. The Addiction Behaviors Checklist: Validation of a New Clinician-Based Measure of Inappropriate Opioid Use in Chronic Pain. J Pain Symptom Manage. 2006:32(4):342-351.

40. Atluri SL, Sudarshan G. Development of a Screening Tool to Detect the Risk of Inappropriate Prescription Opioid Use in Patients with Chronic Pain. Pain Physician. 2004;7(3):333-338

41. McNeely J, Cleland CM, Strauss SM, Palamar JJ, Rotrosen J, Saitz R. Validation of Self-Administered Single-Item Screening Questions (SISQS) for Unhealthy Alcohol and Drug Use in Primary Care Patients. J Gen Intern Med. 2015;30(12):1757-1764.

42. Kaye AD, Jones MR, Kaye AM, et al. Prescription Opioid Abuse in Chronic Pain: An Updated Review of Opioid Abuse Predictors and Strategies to Curb Opioid Abuse (Part 2). Pain Physician. 2017;20(2):S111-S133.

43. Paulozzi LJ, Strickler GK, Kreiner PW, Koris CM. Controlled Substance Prescribing Patterns - Prescription Behavior Surveillance System, Eight States, 2013. MMWR Surveillance Summaries. 16 2015;64(9):1-14.

44. American Psychiatric Association. Diagnostic and Statistical Manual of Mental Disorders. 5th ed. Washington, DC; 2013

45. Substance Abuse and Mental Health Services Administration. Substance Abuse Confidentiality Regulations. Rockville, MD; 2016.

46. Lucado J, Paez K, Elixhauser A. Medication-Related Adverse Outcomes in U.S. Hospitals and Emergency Departments, 2008: Statistical Brief \#109. Rockville, MD: Agency for Healthcare Research and Quality (AHRQ); April 2011.

47. Wheeler M, Oderda GM, Ashburn MA, Lipman AG. Adverse Events Associated with Postoperative Opioid Analgesia: A Systematic Review. J Pain. Jun 2002;3(3):159-180.

48. Noble M, Tregear SJ, Treadwell JR, Schoelles K. Long-Term Opioid Therapy for Chronic Noncancer Pain: A Systematic Review and Meta-Analysis of Efficacy and Safety. J Pain Symptom Manage. Feb 2008;35(2):214-228.

49. Wesson DR, Ling W. The Clinical Opiate Withdrawal Scale (COWS). J Psychoactive Drugs. 2003;35(2):253-259.50.

50. Tompkins DA, Bigelow GE, Harrison JA, Johnson RE, Fudala PJ, Strain EC. Concurrent Validation of the Clinical Opiate Withdrawal Scale (COWS) and Single-Item Indices against the Clinical Institute Narcotic Assessment (CINA) Opioid Withdrawal Instrument. Drug Alcohol Depend. 2009;105(1-2): 154-159.

51. Sullivan JT, Sykora K, Schneiderman J, Naranjo CA, Sellers EM. Assessment of Alcohol Withdrawal: The Revised Clinical Institute Withdrawal Assessment for Alcohol Scale (CIWA-Ar). Br J Addict. 1989;84(11):1353-1357.

52. Rosenblatt RA, Andrilla CH, Catlin M, Larson EH. Geographic and Specialty Distribution of US Physicians Trained to Treat Opioid Use Disorder. Ann Fam Med. Jan-Feb 2015;13(1):23-26.

53. Berna C, Kulich RJ, Rathmell JP. Tapering Long-Term Opioid Therapy in Chronic Noncancer Pain: Evidence and Recommendations for Everyday Practice. Mayo Clin Proc. Jun 2015;90(6):828-842. 